\title{
Psychosocial burden and associated factors among nurses in care homes during the COVID-19 pandemic: findings from a retrospective survey in Germany
}

Christian Hering ( $\nabla$ christian.hering@charite.de)

Institute of Medical Sociology and Rehabilitation Science, Charité - Universitätsmedizin Berlin

Annabell Gangnus

Institute of Medical Sociology and Rehabilitation Science, Charité - Universitätsmedizin Berlin

Andrea Budnick

Institute of Medical Sociology and Rehabilitation Science, Charité - Universitätsmedizin Berlin

Raphael Kohl

Institute of Medical Sociology and Rehabilitation Science, Charité - Universitätsmedizin Berlin

Elisabeth Steinhagen-Thiessen

Department of Endocrinology, Diabetes and Metabolism, Charité - Universitätsmedizin Berlin

\section{Adelheid Kuhlmey}

Institute of Medical Sociology and Rehabilitation Science, Charité - Universitätsmedizin Berlin

Paul Gellert

Institute of Medical Sociology and Rehabilitation Science, Charité - Universitätsmedizin Berlin

\section{Research Article}

Keywords: nurses, care homes, nursing homes, COVID-19, psychosocial burden, depression, anxiety, stress, SARS-CoV-2

Posted Date: August 27th, 2021

DOl: https://doi.org/10.21203/rs.3.rs-850552/v1

License: (c) (i) This work is licensed under a Creative Commons Attribution 4.0 International License. Read Full License

Version of Record: A version of this preprint was published at BMC Nursing on February 10th, 2022. See the published version at https://doi.org/10.1186/s12912-022-00807-3. 


\section{Abstract \\ Background}

Care homes were hit hard by the COVID-19 pandemic. Although high levels of psychosocial burden (i.e., anxiety, depression and stress) during the pandemic have been described for healthcare workers in hospitals, evidence on the psychosocial burden for nurses in care homes during the pandemic is scarce.

\section{Methods}

A total of 811 nurses participated in a retrospective online survey between November 2020 and February 2021. Information about the COVID-19 situation (i.e., working demands, COVID-19 cases in their facility, and COVID-19-related burden) of nurses in German care homes during the first wave of the pandemic (March 2020 to June 2020) was gathered. The Stress Scale of the Depression Anxiety and Stress Scales (SDASS-21), the Generalized Anxiety Disorder Scale-2 (GAD-2), the Patients-Health-Questionnaire-2 (PHQ2), and the Copenhagen Psychosocial Questionnaire (COPSOQ) were used to screen for psychosocial burden.

\section{Results}

Among nurses, $94.1 \%$ stated that work demands since the COVID-19 pandemic increased. Further, $57.5 \%$ showed clinically relevant levels of either stress, anxiety, and/or depression. Multiple regression analysis showed significant associations between COVID-19-related burden and qualification $(p<.01)$, dissatisfaction with COVID-19 management of care home manager $(p<.05)$, COVID-19-related anxiety ( $p$ $<.001)$, and dementia as a focus of care $(p<.05)$. Stress, depression, and anxiety showed associations with COVID-19 related burden at work $(p<.01)$, COVID-19-related anxiety $(p<.001)$, social support ( $p$ $<.01)$, and sense of community $(p<.05)$. Stress was also associated with COVID-19 cases among residents $(p<.05)$, and size of care home $(p<.05)$.

\section{Conclusion}

Short- and long-term strategies (i.e., psychosocial counseling, mandatory team meetings, more highly qualified nurses, additional training) in the work environment of nursing, in crises, but beyond, should be encouraged to reduce the burden on nursing staff in care homes.

\section{Background}

The World Health Organization (WHO) declared the spread of the novel Coronavirus (SARS-CoV-2) as a pandemic on the 11th of March, 2020 [1]. Care homes were hit hard by the pandemic, especially during the first and second pandemic waves. By February 2021, approximately $41 \%$ of COVID-19-deaths 
worldwide were care home residents [2]. In Germany, the estimated share of $50 \%$ of all deaths due to COVID-19 was in care home residents only during the first wave of the pandemic [3]. The European Centre for Disease Prevention and Control (ECDC) pointed out that the residents' age and frailty, heterogeneity of staff qualification, lack of personal protection equipment, and SARS-CoV-2-testing possibilities contributed to the high burden of care homes during COVID-19 [4]. Additionally, care homes with many residents, especially those with dementia, may perceive a higher burden due to the pandemic $[5,6]$. Problems with implementing hygiene measures, the isolation of residents, and the fear of infection and its possible consequences caused a tense work environment $[7,8]$. Therefore, a high psychosocial burden in care home staff was inevitable $[3,6,9,10,11]$. A systematic review and meta-analysis on the global psychosocial burden of health care professionals during COVID-19 showed $37 \%, 41 \%$, and $45 \%$ prevalence rates for depression, anxiety, and stress [12]. In Germany, the most extensive study on psychosocial burden and working conditions of health care workers mainly in hospitals found a prevalence of $19 \%$ for depression and anxiety [13]. Though evidence for the psychosocial burden among health care workers during COVID-19 is vast, research focusing on care home workers is scarce. To our knowledge, there are three studies reporting prevalence rates of different psychopathological symptoms among care home workers; conducted in Italy, Spain, and the United States $[14,15,16]$. Riello and colleagues found prevalence rates of $22 \%$ and $39 \%$ for anxiety and Posttraumatic Stress Disorder (PTSD) among 1071 care home workers in Italy [14]. In Spanish care home workers, a prevalence of $49 \%, 59 \%$, and $71 \%$ was found for depression, anxiety, and PTSD, respectively [15]. Further, 35.4\% of care home workers in Michigan (United States) reported elevated rates of either PTSD, depression, anxiety, and/or stress [16]. Factors associated with increased psychosocial burden were female gender, knowledge about how to do the job, being a nurse, and contact to staff and/or residents with COVID-19. Moreover, support at work was found to be a protective factor. There are currently no studies evaluating the psychosocial burden of nurses in care homes during the first wave of the pandemic in Germany. Moreover, there is a lack of evidence on what structural factors of care homes and personal factors of nurses are associated with the COVID-19-related burden at work, stress, anxiety, and depression.

Our study aimed to investigate and determine associated factors of psychosocial burden among nurses working at care homes during Germany's first wave of the COVID-19 pandemic.

\section{Methods}

\section{Study population}

A retrospective online survey among nurses working in care homes was conducted between the 15th of November 2020 and the 28th of February 2021. The targeted time frame of the survey was between the 1st of March 2020 and the 30th of June 2020 in accordance with the first wave of the pandemic and the following 'Lockdown' in Germany. The survey is part of the cooperation project COVID-Heim, which aims to draw lessons from the pandemic for structural developments in the care home setting by combining various data sources in Germany. The sample consisting of 811 nurses was recruited online via social media. We invited all nurses working in care homes in Germany to participate in our online survey in 
relevant German facebook groups. The survey was provided by a secure web application for building and managing online surveys and databases - Research Electronic Data Capture System (REDCap). The questionnaire was opened 1,884 times and fully completed by 811 nurses. For the anonymous survey, we followed all relevant guidelines and regulations. The online survey was approved by the ethics committee of the Faculty of Medicine of the Charité - Universitäsmedizin Berlin (EA1/254/20).

\section{Measures}

\section{Characteristics of participants and affiliated care homes}

The questionnaire included the following sociodemographic characteristics of the participants: age, sex, qualification (certified nurse, geriatric nurse, nurse in training, health care assistant, other), employment status (permanent, temporary), and risk factors for COVID-19 infections (e.g., >60 years, cardiovascular disease, diabetes mellitus, immunodeficiency, chronic obstructive pulmonary disease) which was taken from the COVID-19 Pandemic Mental Health Questionnaire (CoPaQ) [17]. The characteristics of the

affiliated care homes included questions regarding size of care home (small [1-50 residents], medium [51100 residents], large [ $>100$ residents]), focus of care (e.g. dementia, mental illness, palliative care) and COVID-19 cases residents/staff (no COVID-19 cases, 1-20 COVID-19 cases, 11-20 COVID-19 cases, >20 COVID-19 cases).

\section{COVID-19-related measures}

Working demands since the pandemic. To evaluate the change in working needs since the coronavirus pandemic, we asked nurses how working demands changed during the COVID-19 pandemic since $1^{\text {st }}$ of March 2020, with three possible answer categories: 1) strongly/rather increased 2) did not change 3) rather/strongly decreased.

Satisfaction with COVID-19-related management of care home manager. We asked nurses whether they were satisfied with the COVID-19-related management of their care home manager between the time of $1^{\text {st }}$ of March until $30^{\text {th }}$ of June 2020 (e.g., implementation of protection and hygiene measures against the COVID-19, communication with staff); two answers were possible: 1) very/rather satisfied, 2) very/rather unsatisfied.

COVID-19-related burden at work. Nurses were asked to state to what extent the following possible COVID19-related responsibilities at work were perceived as burden between $1^{\text {st }}$ of March until $30^{\text {th }}$ of June 2020 on a 4-point Likert scale ranging from 0 ) no burden to 3) extremely severe burden. Items were 1) The concern about the wellbeing of the residents; 2) Purchase and consumption of personal protection equipment; 3) Compliance with hygiene guideline of Robert Koch-Institute; 4) Concerns about COVID-19infections among staff; 5) Concerns about COVID-19-infections among residents; 6) Implementation of protection measures (e.g., isolation of COVID-19-infected residents, contact precautions for relatives); 7 ) Small number of COVID-19-tests for residents; 8) Small number of COVID-19-tests for staff; 9) High expectations of relatives. The nine single items were adapted from Hower, Pfaff, and Pförtner [9]. We generated an index - ranging from 0 to 27 - by summing up all items answered. Higher results indicate 
more burden due to COVID-19 at work. The scale obtained a Cronbach's alpha score of 0.82 in our sample, which can be considered as 'good' [18].

COVID-19-related anxiety. Nurses were asked to state to what extent the following statements applied to them in the time from $1^{\text {st }}$ of March until $30^{\text {th }}$ of June 2020 on a 7-point Likert scale ranging from 0 ) does not apply at all to 7) fully applies. Items were 1) I was afraid to get infected with Corona; 2) I was afraid of the consequences of the Corona Pandemic on my life; 3) I was afraid of the consequences for my health if I got infected; 4) I was afraid of the consequences for the health of my relatives if I got infected; 5) I was afraid of the social consequences of Corona and 6) I was afraid of the economic consequences of Corona on my life. The six single items were adapted from Petzold and colleagues [19]. We generated an index - ranging from 0 to 36 - by summing up all item answers. Higher results indicate more COVID-19related anxiety. The scale obtained a Cronbach's alpha score of 0.80 in the present sample, considered 'good' [18].

\section{Stress, anxiety, and depression}

Stress Scale (SDASS-21). Stress symptoms were measured with the Stress Scale of the Depression Anxiety Stress Scale (DASS-21). The subscale consists of 7 items and asks for stress criteria on a 4-point Likert scale ranging from 0) did not apply to me at all to 3) applied to me very much/most of the time. The final scores - ranging from 0 to 21 - were multiplied by two [20, 21]. A score of 14 or less is considered 'normal,' 15-18 'mild,' 19-25 'moderate,' 26-33 'severe,' and 34 or greater is considered 'extremely severe' [22]. The DASS-21 is widely used to study depression, anxiety, and stress in the general population and health care workers $[12,23]$. In the present sample, the validated German version of the stress scale of the DASS-21 obtained a Cronbach's Alpha of 0.88 .

Generalized Anxiety Disorder - 2 (GAD-2). General anxiety symptoms were measured with the ultra-short 2item version of the 7-item scale GAD-7. It incorporates the first two questions of the GAD-7, which are critical components of every anxiety disorder [24]. The score ranges from 0 to 6 . A cut-off value of $\geq 3$ was suggested to detect possible clinically relevant levels of anxiety symptoms. The GAD- 2 is widely used to screen for general signs of anxiety, and its psychometric properties are well documented [25]. In the present sample, the Cronbach's alpha of the GAD-2 was 0.80 .

Patients-Health-Questionnaire - 2 (PHQ-2). Depressive symptoms were measured with the ultra-short 2item version of the 9-item scale PHQ-9 [26]. It incorporates the first two questions of the PHQ-9. The score ranges from 0 to 6 . A cut-off value of $\geq 3$ was suggested to detect possible clinically relevant levels of depressive symptoms. The PHQ-2 has been widely used during the COVID-19 pandemic $[12,13]$. In the present sample, the Cronbach's alpha of the PHQ-2 was 0.82 .

\section{Social Relations at Work}

Social Relations at work were measured by 3 subscales of the validated Copenhagen Psychosocial Questionnaire (COPSOQ) [27]. We used 'support at work (4-item scale)', 'feedback (2-item scale)' and 
'sense of community (2-item scale)' All items were scored on a 5-point Likert scale ranging from 0 ) never/hardly ever to 100) always. In our sample, the 3 subscales obtained Cronbach's alpha scores of $0.83,0.69$, and 0.88 , respectively.

\section{Statistical analysis}

Frequencies, percentages, means, and standard deviations for characteristics of participants and affiliated care homes were generated. Further, normal distribution was tested using the Shapiro-Wilk-Test. The Shapiro-Wilk-Test revealed that the data was not normally distributed. Therefore, relationships between Covid-19-related burden at work, stress, anxiety, depression, and categorical characteristics of participants and affiliated care homes were tested using the Mann-Whitney-U-Test or the Kruskal-WallisTest, respectively. We used Spearman correlation tests to test relationships between COVID-19-related burden at work, stress, anxiety, depression, and continuous variables. Finally, we used multiple regression analyses to determine factors associated with COVID-19-related burden at work, stress, anxiety, and depression. Analyses were performed using IBM SPSS Statistics for Windows, version 25.0 (IBM Corp., Armonk, NY). P values $<.05$ were considered to indicate statistical significance.

\section{Results}

\section{Characteristics of nurses and affiliated care homes}

In total, $N=811$ nurses participated in the survey with a mean $( \pm S D)$ age of 39.5 years $( \pm 10.7)$, the proportion of female nurses was $90.6 \%(n=735)$, and $55.1 \%$ of the nurses $(n=447)$ stated to have at least one risk factor for a severe course of a COVID-19 infection. The majority of participants were geriatric nurses $(72.1 \%, n=585), 96.1 \%(n=771)$ of the nurses had a permanent position in the care home they are working at, $76 \%$ of the nurses worked at medium or large care homes $(n=616)$ and $30.5 \%$ of the nurses confirmed dementia as a focus of care at their care home $(n=247)$. Additionally, most of the nurses reported COVID-19 cases among the residents and the staff $(62.2 \%, n=504 ; 70 \% . n=567)$, respectively, at their care homes. Furthermore, $94.1 \%$ of the nurses confirmed working demands since the pandemic rather or strongly increased $(n=763)$, and $42.3 \%$ stated that they are rather or very unsatisfied with the COVID-19 management of their care home manager $(n=343)$. The mean $( \pm$ SD) for COVID-19related burden and COVID-19-related anxiety were $17.8( \pm 5.5)$ and $22.2( \pm 8.5)$, respectively. Table 1 shows the characteristics of nurses and affiliated care homes in detail.

\section{Prevalence of stress, anxiety, and depression}

In the present sample, $39.2 \%$ of the nurses $(n=308)$ showed moderate to extremely severe stress symptoms according to the stress scale (SDASS-21); 36.5\% $(n=294)$ and $41.5 \%(n=332)$ of the nurses showed clinically relevant symptoms of Anxiety (GAD-2) and Depression (PHQ-2). Altogether, $57.5 \%$ ( $n=$ 466) of the nurses showed values above the cutoff on at least one of the three screening instruments used (SDASS-21, GAD-2, PHQ-2; see Table 1). 


\section{Table 1.}

Characteristics of Participants and affiliated care homes $(N=811)$

n

\section{Characteristics of Participants}

Gender

Female

Male

Divers

Age (years)

$17-39$

$40-67$

Mean (SD)

Qualification

Certified Nurse

Geriatric Nurse

Nurse in Training

Health Care Assistant

Other

Permanent Position (yes)

$\geq 1$ Risk Factor for a severe course of COVID-19

\section{COVID-19-related Measures}

Working demands since the pandemic

Strongly/rather Increased

763

94.1

Did not change

31

11

3.8

Rather/strongly Decreased

Satisfaction with COVID-19 management of care home manager

Very/rather satisfied

467 57.6

Very/rather unsatisfied 343

COVID-19-related burden at work (Mean, SD)

COVID-19-related Anxiety (Mean, SD)
735

90.6

9.1

0.2

54.1

45.9

$39.5(10.7)$

116

14.3

585

72.1

13

1.6

50

6.2

47

5.8

771

96.1

447

55.1

1

1.4




\begin{tabular}{|c|c|c|}
\hline \multicolumn{3}{|c|}{ Stress (SDASS-21), Anxiety (GAD-2) \& Depression (PHQ-2) } \\
\hline \multicolumn{3}{|l|}{ Stress } \\
\hline Mean (SD) & \multicolumn{2}{|c|}{$16.72(10.2)$} \\
\hline Score $\geq 19(N, \%)$ & \multicolumn{2}{|c|}{$308(39.2)$} \\
\hline \multicolumn{3}{|l|}{ Anxiety } \\
\hline Mean (SD) & \multicolumn{2}{|c|}{$2.2(1.8)$} \\
\hline Score $\geq 3(\mathrm{~N}, \%)$ & \multicolumn{2}{|c|}{$294(36.5)$} \\
\hline \multicolumn{3}{|l|}{ Depression } \\
\hline Mean (SD) & \multicolumn{2}{|c|}{$2.5(1.8)$} \\
\hline Score $\geq 3(\mathrm{~N}, \%)$ & \multicolumn{2}{|c|}{$332(41.5)$} \\
\hline Stress, Anxiety and/or Depression ( $N, \%)$ & \multicolumn{2}{|c|}{$466(57.5 \%)$} \\
\hline \multicolumn{3}{|l|}{ Social Relations at work (COPSOQ) } \\
\hline Support at work (Mean, SD) & \multicolumn{2}{|c|}{$60.8(27.4)$} \\
\hline Feedback (Mean, SD) & \multicolumn{2}{|c|}{$46.3(28.6)$} \\
\hline Sense of Community & \multicolumn{2}{|c|}{$72.0(23.0)$} \\
\hline \multicolumn{3}{|l|}{ Characteristics of affiliated Care Homes } \\
\hline \multicolumn{3}{|l|}{ Size of Care Home } \\
\hline Small (1-50 Residents) & 177 & 21.8 \\
\hline Medium (51-100 Residents) & 350 & 43.2 \\
\hline Large (> 101 Residents) & 266 & 32.8 \\
\hline Not Specified & 18 & 2.2 \\
\hline Dementia as focus of care (yes) & 247 & 30.5 \\
\hline COVID-19 cases residents (yes) & 504 & 62.2 \\
\hline COVID-19 cases staff (yes) & 567 & 70.0 \\
\hline
\end{tabular}

\section{Characteristics of nurses in relation with psychosocial burden}

We further investigated the relationship between COVID-19-related burden at work, stress, anxiety, depression, and characteristics of participants and affiliated care homes (see Table 2). At first, nurses rather or very unsatisfied with COVID-19 management of their care home manager showed significantly higher scores on all 4 scales than those rather or very satisfied $(p<.001)$. Moreover, we found that older nurses perceived a significantly higher COVID-19-related burden at work than younger nurses $(p<.01)$. 
Also, nurses working in care homes with dementia as a focus of care perceived a significantly higher COVID-19-related burden at work than those who do not $(p<.01)$. In addition to that, female nurses had significantly higher scores on the stress scale of the DASS-21 compared to their male counterparts $(p<$ .05). Also, nurses with at least 1 risk factor for a severe course of COVID-19 showed significantly higher anxiety scores than those with no risk factors $(p<.05)$. Finally, younger nurses $(17-39$ years) and nurses with at least 1 risk factor for a severe course of COVID-19 showed significantly higher scores of Depression compared to their counterparts $(p<.01, p<.05)$. Correlations between scales can be found in the Additional file 1.

\section{Multivariate associations between characteristics of nurses and psychosocial burden}

Multivariate results indicate that COVID-19-related burden at work was significantly associated with qualification: health care assistants perceived significantly less COVID-19-related burden at work compared to certified nurses ( $\beta=-.12,95 \% \mathrm{Cl}$ - -.21, -.04; see Table 3). Furthermore, COVID-19-related burden at work was significantly associated to the satisfaction with the COVID-19 management of the care home manager with those being rather or very unsatisfied perceived significantly higher burden $(\beta=$ $.10,95 \% \mathrm{Cl}: .02, .17)$. 


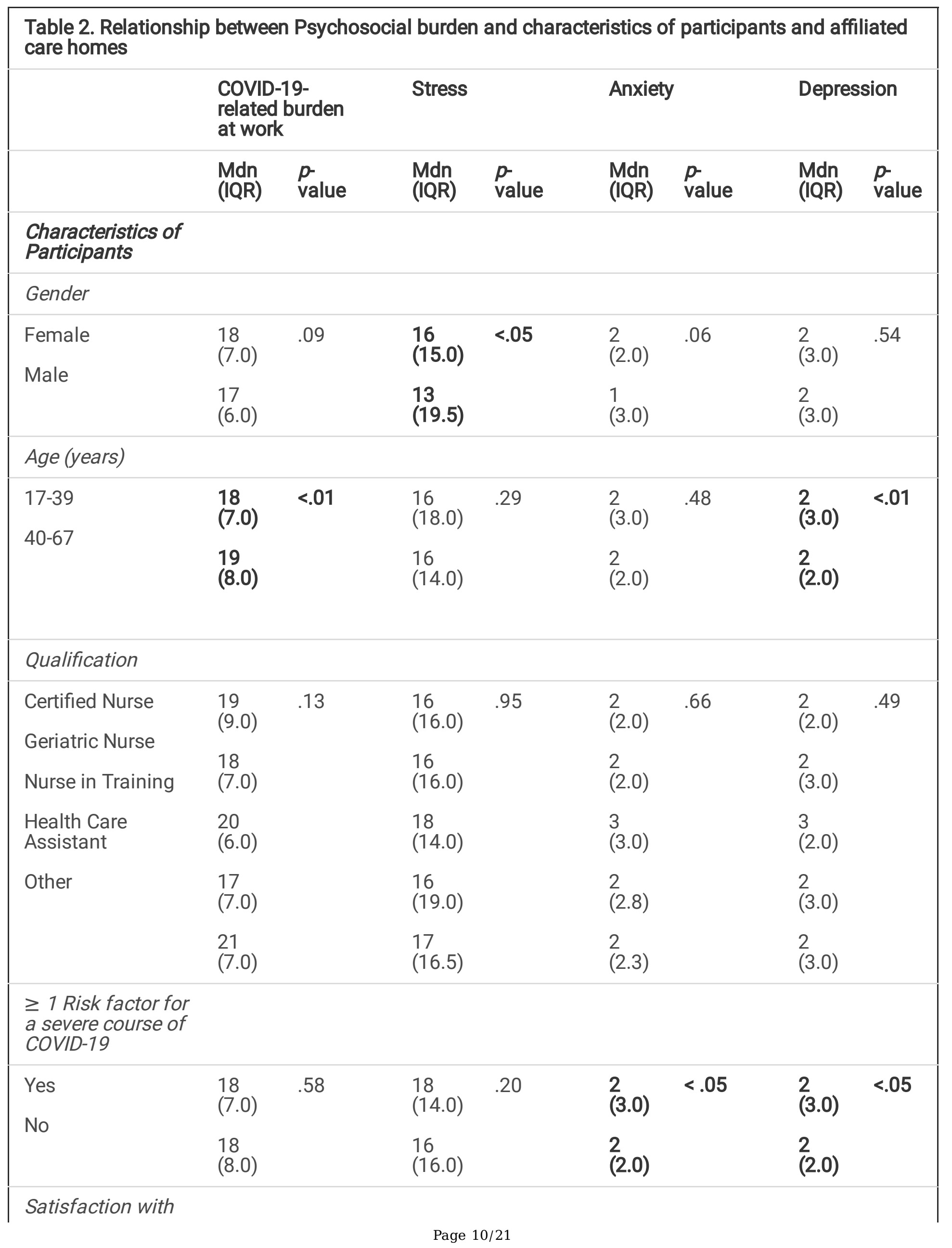




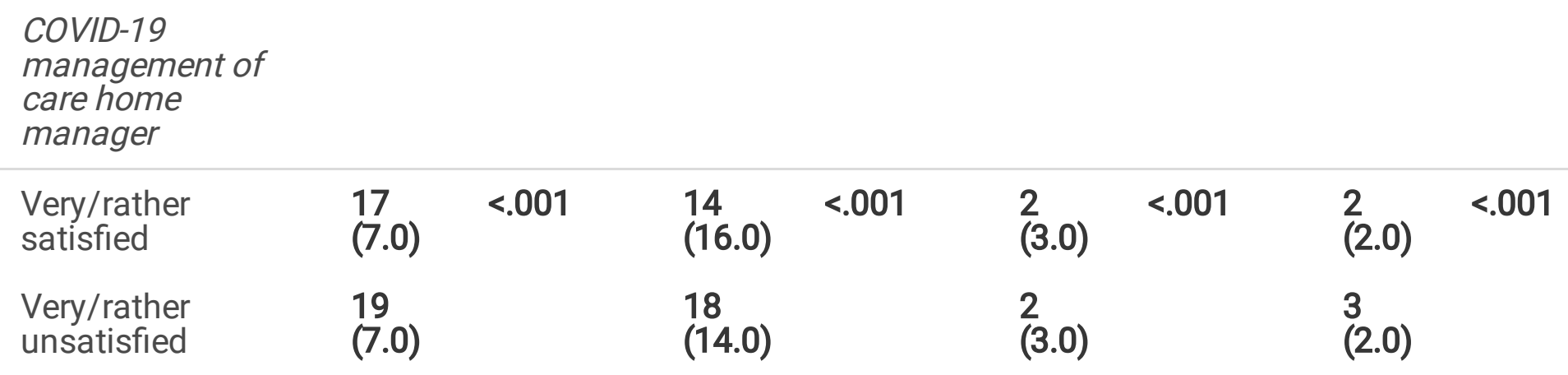

\section{Characteristics of affiliated Care Homes}

Size of Care Home

\begin{tabular}{|c|c|c|c|c|c|c|c|}
\hline $\begin{array}{l}\text { Small (1-50 } \\
\text { Residents) }\end{array}$ & $\begin{array}{l}18 \\
(7.0)\end{array}$ & .19 & $\begin{array}{l}18 \\
(16.0)\end{array}$ & .67 & $\begin{array}{l}2 \\
(2.8)\end{array}$ & .67 & $\begin{array}{l}2 \\
(2.0)\end{array}$ \\
\hline $\begin{array}{l}\text { Medium (51-100 } \\
\text { Residents) }\end{array}$ & $\begin{array}{l}18 \\
(8.0)\end{array}$ & & $\begin{array}{l}16 \\
(16.0)\end{array}$ & & $\begin{array}{l}2 \\
(2.0)\end{array}$ & & $\begin{array}{l}2 \\
(3.0)\end{array}$ \\
\hline $\begin{array}{l}\text { Large (> } 101 \\
\text { Residents) }\end{array}$ & $\begin{array}{l}18 \\
(8.0)\end{array}$ & & $\begin{array}{l}16 \\
(16.0)\end{array}$ & & $\begin{array}{l}2 \\
(3.0)\end{array}$ & & $\begin{array}{l}2 \\
(3.0)\end{array}$ \\
\hline
\end{tabular}

Dementia as

focus of care

\begin{tabular}{|c|c|c|c|c|c|c|c|c|}
\hline \multirow{2}{*}{$\begin{array}{l}\text { Yes } \\
\text { No }\end{array}$} & $\begin{array}{l}19 \\
(8.0)\end{array}$ & $<.01$ & $\begin{array}{l}16 \\
(16.0)\end{array}$ & .61 & $\begin{array}{l}2 \\
(3.0)\end{array}$ & .88 & $\begin{array}{l}2 \\
(3.0)\end{array}$ & .65 \\
\hline & $\begin{array}{l}18 \\
(7.3)\end{array}$ & & $\begin{array}{l}16 \\
(14.0)\end{array}$ & & $\begin{array}{l}2 \\
(2.0)\end{array}$ & & $\begin{array}{l}2 \\
\text { (3.0) }\end{array}$ & \\
\hline
\end{tabular}

COVID-19 cases

residents

\begin{tabular}{|c|c|c|c|c|c|c|c|c|}
\hline \multirow{2}{*}{$\begin{array}{l}\text { Yes } \\
\text { No }\end{array}$} & $\begin{array}{l}18 \\
(7.0)\end{array}$ & .29 & $\begin{array}{l}16 \\
(14.0)\end{array}$ & .24 & $\begin{array}{l}2 \\
(3.0)\end{array}$ & .06 & $\begin{array}{l}2 \\
(3.0)\end{array}$ & .25 \\
\hline & \multicolumn{2}{|l|}{$\begin{array}{l}18 \\
(8.0)\end{array}$} & \multicolumn{2}{|l|}{$\begin{array}{l}16 \\
(16.0)\end{array}$} & \multicolumn{2}{|l|}{$\begin{array}{l}2 \\
(3.0)\end{array}$} & \multicolumn{2}{|l|}{$\begin{array}{l}2 \\
(3.0)\end{array}$} \\
\hline \multicolumn{9}{|c|}{$\begin{array}{l}\text { COVID-19 cases } \\
\text { staff }\end{array}$} \\
\hline \multirow{2}{*}{$\begin{array}{l}\text { Yes } \\
\text { No }\end{array}$} & $\begin{array}{l}18 \\
(7.0)\end{array}$ & \multirow[t]{2}{*}{.20} & $\begin{array}{l}16 \\
(16.0)\end{array}$ & \multirow[t]{2}{*}{.80} & $\begin{array}{l}2 \\
(2.0)\end{array}$ & \multirow[t]{2}{*}{.47} & $\begin{array}{l}2 \\
(3.0)\end{array}$ & \multirow[t]{2}{*}{.91} \\
\hline & $\begin{array}{l}18 \\
(8.0)\end{array}$ & & $\begin{array}{l}16 \\
(16.0)\end{array}$ & & $\begin{array}{l}2 \\
(2.5)\end{array}$ & & $\begin{array}{l}2 \\
(3.0)\end{array}$ & \\
\hline
\end{tabular}

Note. Mdn = Median. IQR = Interquartile range. Significant values are shown in bold type. 
COVID-19-related burden at work was also significantly associated to COVID-19-related anxiety $(\beta=.45$, $95 \% \mathrm{Cl}: .38, .52)$ and working in a care home with dementia as focus of care $(\beta=.07,95 \% \mathrm{Cl}: .00, .14)$. There were significantly negative associations between stress and the age of the nurses $(\beta=-.08,95 \% \mathrm{Cl}$ : $-.16,-.01)$, support at work ( $\beta=-.18,95 \% \mathrm{Cl}:-.29,-.07)$, sense of community $(\beta=-.09,95 \% \mathrm{Cl}:-.18,-.01)$ and size of the care home. Nurses working in large care homes were significantly less stressed compared to nurses working in small care homes $(\beta=-.10,95 \% \mathrm{Cl}$ : -.19, -.01). In contrast, there was a significantly positive association between stress and COVID-19-related burden at work ( $\beta=.19,95 \% \mathrm{Cl}$. .11, .28), COVID-19-related anxiety ( $\beta=.26,95 \% \mathrm{Cl} .18, .34)$ and COVID-19 cases among residents $(\beta=.10,95 \% \mathrm{Cl}$ : $.00, .19)$. Anxiety was significantly positively associated with COVID-19-related burden at work $(\beta=.16$, $95 \% \mathrm{Cl}: .08, .25)$ and COVID-19-related anxiety $(\beta=.18,95 \% \mathrm{Cl}: .10, .26)$, while it was significantly negative associated with support at work $(\beta=-.16,95 \% \mathrm{Cl}:-.27,-.05)$, and sense of community $(\beta=-.11$, $95 \% \mathrm{Cl}:-.20,-.03)$. Depression was significantly associated with qualification, with geriatric nurses showing more depressive symptoms compared to certified nurses $(\beta=.11,95 \% \mathrm{Cl}$ : .02, .21), with COVID19-related burden at work ( $\beta=.15,95 \% \mathrm{Cl}: .06, .23)$, and COVID-19-related anxiety $(\beta=.15,95 \% \mathrm{Cl}$ : .07, .23). A significantly negative association with depression was shown with support at work $(\beta=-.25,95 \%$ Cl: $-.35,-.14)$, and a sense of community ( $\beta=-.11,95 \% \mathrm{Cl}:-.20,-.02$; see Table 3$)$. There were no significant associations between the presence of at least 1 risk factor for a severe course of COVID-19, feedback and COVID-19 cases among staff with one of the four scales.

\section{Discussion}

The present study aimed to investigate stress, anxiety, depression, and COVID-19-related burden at work for nurses in care homes during the first wave of COVID-19 in Germany. Further, we wanted to determine factors associated with the psychosocial burden of nurses in care homes. We have found that COVID-19related burden was lower in health care assistants, was associated with higher COVID-19-related anxiety, and with dementia as a focus of care. Stress was significantly higher in younger healthcare workers, was associated with higher anxiety about COVID-19, with increased COVID-19-related work burden and lack of support and sense of community at work. Stress was higher where more COVID-19 cases were 
Table 3

Multiple Regression Analysis on Covid-19-related burden at work, Stress (SDASS-21), Anxiety (GAD-2) and Depression (PHQ-2)

\begin{tabular}{|c|c|c|c|c|c|c|c|c|}
\hline & \multicolumn{2}{|c|}{$\begin{array}{l}\text { Covid-19- } \\
\text { related burden } \\
\text { at work }\end{array}$} & \multicolumn{2}{|l|}{ Stress } & \multicolumn{2}{|c|}{ Anxiety } & \multicolumn{2}{|c|}{ Depression } \\
\hline & $\begin{array}{l}\beta \\
(95 \% \\
\text { Cl) }\end{array}$ & $\begin{array}{l}\mathrm{p}- \\
\text { value }\end{array}$ & $\begin{array}{l}\beta \\
(95 \% \\
\mathrm{Cl})\end{array}$ & $\begin{array}{l}\mathrm{p}- \\
\text { value }\end{array}$ & $\begin{array}{l}\beta \\
(95 \% \\
\text { CI) }\end{array}$ & $\begin{array}{l}\mathrm{p}- \\
\text { value }\end{array}$ & $\begin{array}{l}\beta \\
(95 \% \\
\mathrm{Cl})\end{array}$ & $\begin{array}{l}\mathrm{p}- \\
\text { value }\end{array}$ \\
\hline \multicolumn{9}{|l|}{$\begin{array}{l}\text { Characteristics } \\
\text { of participants }\end{array}$} \\
\hline Gender (Male) & $\begin{array}{l}-.06 \\
(-.12 \\
.01)\end{array}$ & .12 & $\begin{array}{l}-.04 \\
(-.11 \\
.03)\end{array}$ & .29 & $\begin{array}{l}-.06 \\
(-.14 ; \\
.01)\end{array}$ & .10 & $\begin{array}{l}-.00 \\
(-.07 \\
.07)\end{array}$ & .98 \\
\hline Age (years) & $\begin{array}{l}.05 \\
(-.02 \\
.12)\end{array}$ & .14 & $\begin{array}{l}-.08 \\
(-.16 ; \\
-.01)\end{array}$ & $<.05$ & $\begin{array}{l}-.04 \\
(-.12 ; \\
.04)\end{array}$ & .29 & $\begin{array}{l}-.07 \\
(-.14 ; \\
.00)\end{array}$ & .06 \\
\hline \multicolumn{9}{|l|}{ Qualification } \\
\hline $\begin{array}{l}\text { Nurse } \\
\text { [Reference] }\end{array}$ & $\begin{array}{l}-.05 \\
(-.14 \\
.04)\end{array}$ & $\begin{array}{l}.31 \\
.85\end{array}$ & $\begin{array}{l}-.00 \\
(-.10 \\
.09)\end{array}$ & $\begin{array}{l}.97 \\
.63\end{array}$ & $\begin{array}{l}.08 \\
(-.02 ; \\
.18)\end{array}$ & $\begin{array}{l}.12 \\
.31\end{array}$ & $\begin{array}{l}.11 \\
(.02 \\
.21)\end{array}$ & $\begin{array}{l}<.05 \\
.39\end{array}$ \\
\hline $\begin{array}{l}\text { Gerratric Nurse } \\
\text { Nurse in } \\
\text { Training }\end{array}$ & $\begin{array}{l}.01 \\
(-.07 \\
.08)\end{array}$ & $\begin{array}{l}<.01 \\
.31\end{array}$ & $\begin{array}{l}-.02 \\
(-.09 \\
.06)\end{array}$ & $\begin{array}{l}.17 \\
.98\end{array}$ & $\begin{array}{l}.04 \\
(-.04 ; \\
.12)\end{array}$ & $\begin{array}{l}.14 \\
.94\end{array}$ & $\begin{array}{l}.03 \\
(-.04 ; \\
.11)\end{array}$ & $\begin{array}{l}.07 \\
.63\end{array}$ \\
\hline $\begin{array}{l}\text { Health Care } \\
\text { Assistant }\end{array}$ & $\begin{array}{l}-.12 \\
(-.21 ; \\
-.04)\end{array}$ & & $\begin{array}{l}.06 \\
(-.03 \\
.14)\end{array}$ & & $\begin{array}{l}.07 \\
(-.02 ; \\
.15)\end{array}$ & & $\begin{array}{l}.08 \\
(-.01 ; \\
.16)\end{array}$ & \\
\hline Сाи & $\begin{array}{l}.04 \\
(-.04 \\
.12)\end{array}$ & & $\begin{array}{l}-.00 \\
(-.08 \\
.08)\end{array}$ & & $\begin{array}{l}.00 \\
(-.08 ; \\
.09)\end{array}$ & & $\begin{array}{l}.02 \\
(-.06 ; \\
.10)\end{array}$ & \\
\hline $\begin{array}{l}\geq 1 \text { Risk factor } \\
\text { for severe } \\
\text { course of } \\
\text { COVID-19 (yes) }\end{array}$ & $\begin{array}{l}.03 \\
(-.04 \\
.10)\end{array}$ & .38 & $\begin{array}{l}.01 \\
(-.06 \\
.08)\end{array}$ & .84 & $\begin{array}{l}.06 \\
(-.02 ; \\
.13)\end{array}$ & .12 & $\begin{array}{l}.03 \\
(-.05 ; \\
.09)\end{array}$ & .51 \\
\hline $\begin{array}{l}\text { COVID-19- } \\
\text { related } \\
\text { Measures }\end{array}$ & & & & & & & & \\
\hline $\begin{array}{l}\text { Satisfaction } \\
\text { with COVID-19 } \\
\text { management } \\
\text { of care home } \\
\text { manager } \\
\text { (very/rather } \\
\text { unsatisfied) }\end{array}$ & $\begin{array}{l}.10 \\
(.02 ; \\
.17)\end{array}$ & $<.05$ & $\begin{array}{l}.01 \\
(-.07 \\
.10)\end{array}$ & .73 & $\begin{array}{l}.00 \\
(-.08 ; \\
.08)\end{array}$ & .99 & $\begin{array}{l}.03 \\
(-.05 ; \\
.11)\end{array}$ & .49 \\
\hline
\end{tabular}




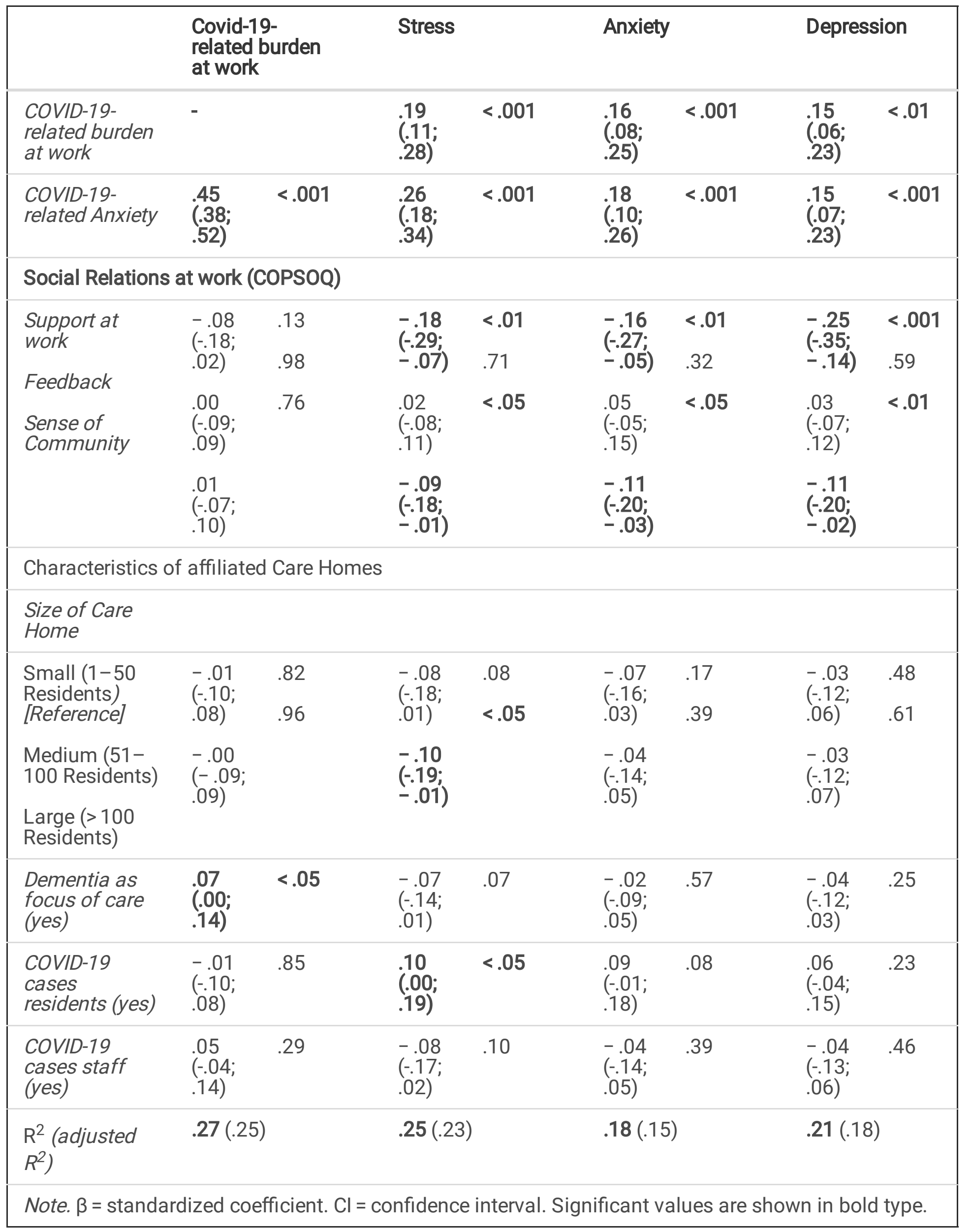


diagnosed, but was less in larger care homes. Anxiety and depression were associated with higher COVID19-related anxiety, with increased COVID-19 related work burden, lack of support, and sense of community at work.

In Comparison to evidence from the Organisation of Economic Co-operation and Development (OECD), providing data on the long-term care workforce of 38 countries worldwide, the present study sample was slightly younger, higher qualified, and more often in a permanent working status [28]. Moreover, $55 \%$ of the nurses reported at least one risk factor for a severe course of COVID-19, which is in line with a previous study by Greene and Gibson, which found a similar percentage (50\%) of COVID-19 risk factors in the long term care workforce of the United States [29].

Our study supports evidence from other countries that the COVID-19 pandemic had a high impact on working demands and workload of care home staff $[7,8,11,30]$. In the presen sample, the vast majority of nurses reported an increased working demand since the pandemic, with $42 \%$ stating that they were unsatisfied with the COVID-19 management of their care home manager. Prior research showed that care home staff often did not feel involved in decision-making processes and did not feel heard by the management of their care homes. A lack of communication between management and staff caused uncertainty and distress about handling the pandemic and implementing measures to prevent infections $[31,32,33]$.

The present study showed increased prevalence rates of stress, anxiety, and depression (57.5\%). About $39 \%$ of the nurses showed moderate to extremely severe stress symptoms, $36.5 \%$ showed clinically significant anxiety, and $41.5 \%$ showed clinically significant depression. The prevalence rates found are different from those in Italy, Spain, and Michigan (USA) [14-16]. In Northern Italy, a prevalence rate of $22 \%$ for anxiey was found; $59 \%$ for anxiety and $49 \%$ for depression were found in Spain. Our findings may be due to the different impacts of the pandemic on countries and structural differences in care homes. Additionally, prior studies included all staff working in care homes, not exclusively nursing staff. Nevertheless, the prevalence rates found in the present study are similar to the meta-analysis on the global psychosocial burden of health care workers during COVID-19 [12]. After analyzing 83 studies, a pooled prevalence of $37 \%$ for depression, $41 \%$ for anxiety, and $45 \%$ for stress among health care workers worldwide were found. Compared to prevalence rates for depression and anxiety found in German healthcare workers in general (19\%) and the general population (22\%), prevalence rates for depression and anxiety were higher in the present sample $[13,19]$.

Besides, our findings showed that COVID-19-related burden at work (e.g., lack of personal protection equipment, a small number of COVID-19-Tests for residents and staff) was positively associated with the dissatisfaction with COVID-19 management of care home management, COVID-19- related anxiety, and dementia as a focus of care. This is in line with previous research showing that there was uncertainty about implemented hygiene measures due to a lack of communication and information and not being included in decision-making processes by care home management during the pandemic [8, 31, 32, 33]. A higher burden for care home staff working with residents with dementia, in general, was a concern even 
before the pandemic [34]. Compared to certified nurses, health care assistants were significantly less burdened due to COVID-19 at work. Prior research showed these ambiguous findings. Some results also imply that health care assistants are less prone to burnout and stress in general and due to COVID-19 than certified nurses $[35,36,37,38]$. Other studies did not show any differences or even the opposite [39, 40].

Stress, anxiety, and depression were associated with COVID-19-related burden at work, COVID-19-related anxiety, less support at work, and less sense of community. Additionally, stress was negatively associated with age and working in a large care home and positively associated with working in a care home with COVID-19 cases among residents. Though we hypothesized that working in a large care home may be associated with increased psychosocial burden, our results showed the opposite regarding stress symptoms. A possible explanation could be that larger care homes had more possibilities to implement specific hygiene measures, i.e., isolate infected residents, divide areas, and build different caregroups where only certain nurses would regularly take care of the same residents.

Our study has strengths and limitations. Strengths include a large sample size and detailed, wellvalidated, and widely used assessments and questionnaires to generate prevalence rates of stress, anxiety, and depression for german nursing staff in care homes. Certain limitations need to be considered. At first, the study sample was recruited online via social media only. Thus, nursing staff with limited access to the internet or web-enabled devices might not have participated in this survey. Further, our study sample was slightly younger with higher qualifications than Germany's usual long-term care workforce [41], raising the issue of selection bias. Both problems may limit generalizability to the entire workforce of nursing staff in german care homes. Moreover, although we took the number of COVID-19 cases into account, our data does not differentiate for regions or COVID-19 hotspots, though there was variation in how much certain areas of Germany were affected by the pandemic. Finally, the retrospective nature of our survey may have biased answers as subsequent events may have influenced the answering of nursing staff.

\section{Conclusions}

In summary, high psychosocial burden among nursing staff in care homes in Germany has been shown. These results add new information into the understudied area of care home staff burden and the COVID19 pandemic. The results could yield strategies that needed to be addressed to help and support nursing staff during a crisis and beyond. Regular psychosocial counseling and programs for the prevention of mental illnesses could be a strategy to buffer the high demands of the nursing job and to prevent the worsening of already existing distress symptoms. Furthermore, social support and a sense of community are essential to cope with an extraordinary circumstance like the pandemic. Regular team meetings, counseling with the care home management, and involving staff in decision-making processes could help strengthen the bond between staff and management and buffer future crises.

\section{Declarations}




\section{Ethics approval and consent to participate}

The retrospective online survey as part of the project Covid-Heim was approved by the ethics committee of the Faculty of Medicine of the Charite - Universitäsmedizin Berlin (reference number: EA1/254/20). All data were provided and analyzed anonymously. All respondents provided written informed consent for participation.

\section{Consent for publication}

Informed Consent for publication of anonymous data was obtained from participants within the online survey.

\section{Availability of data and materials}

The dataset used for the current retrospective survey is available from the corresponding author on reasonable request.

\section{Competing interests}

The authors declare that they have no competing interests.

\section{Funding}

The project "COVID-Heim" is funded by Germany's GKV Spitzenverband (The National Association of Statutory Health insurance Funds). "The National Association of Statutory Health Insurance Funds has taken on a central role in the German healthcare system as from 1 July 2008, being the central association of the health insurance funds at federal level in accordance with section 217 a of Book V of the German Social Code (SGB V) [https://www.gkv-spitzenverband.de/english/about_us/about_us.jsp]" The funding source has no implications for the conduct, and the result reported in this study.

\section{Authors' contributions}

The authors contributed to the article as follows: $\mathrm{CH}$ analyzed the data. $\mathrm{CH}, \mathrm{PG}, \mathrm{EST}$, and AK interpreted the data and drafted the initial version of the paper. AK, PG, EST, CH, AG, and RK conceived and designed the study. AK, PG, EST, $A G, A B$ and RK assisted with the drafting of data collection instruments. $C H, A K$, and $P G$ were major contributors in writing the manuscript. All authors critically revised the initial draft of the manuscript. All authors contributed to revisions of the paper and have approved the manuscript presented here.

\section{Acknowledgments}

We thank all nursing staff in care homes for their extraordinary work during the pandemic and that they took the time to respond to our survey. 


\section{References}

1. Cucinotta D, Vanelli M. WHO declares COVID-19 a pandemic. Acta Bio Medica: Atenei Parmensis. 2020;91(1):157.

2. Comas-Herrera A, Zalakaín J, Lemmon E, Henderson D, Litwin C, Hsu AT, et al. Mortality associated with COVID-19 in care homes: international evidence. Article in LTCcovid org, international long-term care policy network, CPEC-LSE. 2020;14.

3. Rothgang H, Wolf-Ostermann K, Domhoff D, Friedrich AC, Heinze F, Preuss B, et al. Care Homes and COVID-19: Results of an Online Survey in Germany. LTCcovid, International Long-Term Care Policy Network, CPEC-LSE. 2020.

4. Danis K, Fonteneau L, Georges S, Daniau C, Bernard-Stoecklin S, Domegan L, et al. High impact of COVID-19 in long-term care facilities, suggestion for monitoring in the EU/EEA, May 2020. Eurosurveillance. 2020;25(22):2000956.

5. Giri S, Chenn LM, Romero-Ortuno R. Nursing homes during the COVID-19 pandemic: a scoping review of challenges and responses. European Geriatric Medicine. 2021:1-10.

6. Gordon AL, Goodman C, Achterberg W, Barker RO, Burns E, Hanratty B, et al. Commentary: COVID in care homes-challenges and dilemmas in healthcare delivery. Age and ageing. 2020;49(5):701-5

7. White EM, Wetle TF, Reddy A, Baier RR. Front-line nursing home staff experiences during the COVID19 pandemic. Journal of the American Medical Directors Association. 2021;22(1):199-203.

8. Sarabia-Cobo C, Pérez V, De Lorena P, Hermosilla-Grijalbo C, Sáenz-Jalón M, Fernández-Rodríguez A, et al. Experiences of geriatric nurses in nursing home settings across four countries in the face of the COVID-19 pandemic. Journal of Advanced Nursing. 2021;77(2):869-78.

9. Hower KI, Pfaff H, Pförtner T-K. Is time a healer? Course of demands during the COVID-19 pandemic in long-term care: a repeated cross-sectional survey in Germany. Journal of public health (Oxford, England). 2021.

10. Thompson D-C, Barbu M-G, Beiu C, Popa LG, Mihai MM, Berteanu M, et al. The impact of COVID-19 pandemic on long-term care facilities worldwide: an overview on international issues. BioMed research international. 2020;2020.

11. Blanco-Donoso LM, Moreno-Jiménez J, Gallego-Alberto L, Amutio A, Moreno-Jiménez B, Garrosa E. Satisfied as professionals, but also exhausted and worried!!: The role of job demands, resources and emotional experiences of Spanish nursing home workers during the COVID-19 pandemic. Health \& Social Care in the Community. 2021.

12. Mahmud S, Hossain S, Muyeed A, Islam MM, Mohsin M. The Global Prevalence of Depression, Anxiety, Stress, and, Insomnia and Its' Changes among Health Professionals during COVID-19 Pandemic: A Rapid Systematic Review and Meta-Analysis. Heliyon. 2021:e07393.

13. Schug C, Morawa E, Geiser F, Hiebel N, Beschoner P, Jerg-Bretzke L, et al. Social Support and Optimism as Protective Factors for Mental Health among 7765 Healthcare Workers in Germany 
during the COVID-19 Pandemic: Results of the VOICE Study. International Journal of Environmental Research and Public Health. 2021;18(7):3827.

14. Riello M, Purgato M, Bove C, MacTaggart D, Rusconi E. Prevalence of post-traumatic symptomatology and anxiety among residential nursing and care home workers following the first COVID-19 outbreak in Northern Italy. Royal Society open science. 2020;7(9):200880.

15. Martín J, Padierna Á, Villanueva A, Quintana JM. Evaluation of the Mental Health of Care Home Staff in the Covid-19 Era. What price did care home workers pay for standing by their patients? International Journal of Geriatric Psychiatry. 2021.

16. Daugherty AM, Arble EP. Prevalence of mental health symptoms in residential healthcare workers in Michigan during the covid-19 pandemic. Psychiatry Research. 2020;291:113266.

17. Rek SV, Freeman D, Reinhard M, Bühner M, Keeser D, Padberg F. The COVID-19 Pandemic Mental Health Questionnaire (CoPaQ): Introducing a comprehensive measure of the psychosocial impact of the current coronavirus crisis. Open Sci Framew. 2020;

18. Gliem JA, Gliem RR, editors. Calculating, interpreting, and reporting Cronbach's alpha reliability coefficient for Likert-type scales2003: Midwest Research-to-Practice Conference in Adult, Continuing, and Community Education. 2003

19. Petzold MB, Bendau A, Plag J, Pyrkosch L, Mascarell Maricic L, Betzler F, et al. Risk, resilience, psychological distress, and anxiety at the beginning of the COVID-19 pandemic in Germany. Brain and behavior. 2020;10(9):e01745.

20. Beaufort IN, De Weert-Van Oene GH, Buwalda VAJ, De Leeuw JRJ, Goudriaan AE. The Depression, Anxiety and Stress Scale (DASS-21) as a Screener for Depression in Substance Use Disorder Inpatients: A Pilot Study. Eur Addict Res. 2017;23(5):260-8. 20.

21. Ramón-Arbués E, Gea-Caballero V, Granada-López JM, Juárez-Vela R, PellicerGarcía B, Antón-Solanas I. The prevalence of depression, anxiety and stress and their associated factors in college students. Int J Environ Res Public Health. 2020;17(19):1-15.

22. Lovibond SH, Lovibond PF. Manual for the Depression Anxiety Stress Scales. Vol. 56, Psychology Foundation of Australia. 1995.

23. Wang C, Pan R, Wan X, Tan Y, Xu L, Mclntyre RS, et al. A longitudinal study on the mental health of general population during the COVID-19 epidemic in China. Brain, behavior, and immunity. 2020;87:40-8.

24. Sapra A, Bhandari P, Sharma S, Chanpura T, Lopp L. Using generalized anxiety disorder-2 (GAD-2) and GAD-7 in a primary care setting. Cureus. 2020;12(5).

25. Plummer F, Manea L, Trepel D, McMillan D. Screening for anxiety disorders with the GAD-7 and GAD2: a systematic review and diagnostic metaanalysis. General hospital psychiatry. 2016;39:24-31.

26. Löwe B, Kroenke K, Gräfe K. Detecting and monitoring depression with a two-item questionnaire (PHQ-2). Journal of psychosomatic research. 2005;58(2):163-71.

27. Nübling M, Stößel U, Hasselhorn H-M, Michaelis M, Hofmann F. Measuring psychological stress and strain at work-Evaluation of the COPSOQ Questionnaire in Germany. GMS Psycho-Social Medicine. 
2006;3.

28. Organisation for Economic Co-operation and Development. Who Cares?: Attracting and Retaining Care Workers for the Elderly: OECD; 2020.

29. Greene J, Gibson DM. Workers at long-term care facilities and their risk for severe COVID-19 illness. Preventive Medicine. 2021;143:106328.

30. Blanco-Donoso LM, Moreno-Jiménez J, Amutio A, Gallego-Alberto L, Moreno-Jiménez B, Garrosa E. Stressors, job resources, fear of contagion, and secondary traumatic stress among nursing home workers in face of the COVID-19: the case of Spain. Journal of Applied Gerontology. 2021;40(3):24456.

31. Kaelen S, van den Boogaard W, Pellecchia U, Spiers S, De Cramer C, Demaegd G, et al. How to bring residents' psychosocial well-being to the heart of the fight against Covid-19 in Belgian nursing homes -A qualitative study. Plos one. 2021;16(3):e0249098.

32. Lethin C, Kenkmann A, Chiatti C, Christensen J, Backhouse T, Killett A, et al., editors. Organizational Support Experiences of Care Home and Home Care Staff in Sweden, Italy, Germany and the United Kingdom during the COVID-19 Pandemic. Healthcare; 2021: Multidisciplinary Digital Publishing Institute.

33. Rutten JE, Backhaus R, Ph Hamers J, Verbeek H. Working in a Dutch nursing home during the COVID19 pandemic: Experiences and lessons learned. Nursing Open. 2021.

34. Baker C, Huxley P, Dennis M, Islam S, Russell I. Alleviating staff stress in care homes for people with dementia: protocol for stepped-wedge cluster randomised trial to evaluate a web-based MindfulnessStress Reduction course. BMC psychiatry. 2015;15(1):1-9.

35. Marques M, Alves E, Queirós C, Norton P, Henriques A. The effect of profession on burnout in hospital staff. Occupational Medicine. 2018;68(3):207-10.

36. Kennedy BR. Stress and burnout of nursing staff working with geriatric clients in long-term care. Journal of Nursing Scholarship. 2005;37(4):381.

37. Lacher S, De Geest S, Denhaerynck K, Trede I, Ausserhofer D. The Quality of Nurses' Work Environment and Workforce Outcomes From the Perspective of Swiss Allied Healthcare Assistants and Registered Nurses: A Cross-Sectional Survey. Journal of Nursing Scholarship. 2015;47(5):45867.

38. Çelmeçe N, Menekay M. The effect of stress, anxiety and burnout levels of healthcare professionals caring for COVID-19 patients on their quality of life. Frontiers in psychology. 2020;11:3329.

39. Martínez-López JÁ, Lázaro-Pérez C, Gómez-Galán J. Burnout among Direct-Care Workers in Nursing Homes during the COVID-19 Pandemic in Spain: A Preventive and Educational Focus for Sustainable Workplaces. Sustainability. 2021;13(5):2782.

40. El Haj M, Allain P, Annweiler C, Boutoleau-Bretonnière $C$, Chapelet $G$, Gallouj $K$, et al. Burnout of healthcare workers in acute care geriatric facilities during the COVID-19 crisis: An online-based study. Journal of Alzheimer's Disease. 2020(Preprint):1-6.

41. Federal Statistical Office. Pflegestatistik 2019. Wiesbaden: Statistisches Bundesamt. 2020. p. 39. 


\section{Supplementary Files}

This is a list of supplementary files associated with this preprint. Click to download.

- Additionalfile1.docx 